\title{
Comparative morphological studies of raw parts of the most common species of Thymus in Ukraine
}

\author{
Original research article/Review \\ Minarchenko V. ${ }^{1,4}$, Tymchenko I. ${ }^{2}$, Glushchenko L. ${ }^{3}$, Pidchenko V4凶 \\ ${ }_{1,2}$ M.G. Kholodny Institute of Botany of the NAS of \\ Ukraine, 2 Tereshchenkivska Street, \\ 01004, Kyiv, Ukraine \\ ${ }^{3}$ Experimental Station of Medicinal Plants, Institute of \\ Agroecology and Nature Management of the National \\ Academy of Agricultural Sciences of Ukraine, 16A \\ Pokrovska Street, 37535, Berezotocha, Ukraine. \\ ${ }^{1,4}$ Bogomolets National Medical University, Department \\ of Pharmacognosy and Botany, 22 Pushkinska Street, \\ 01004, Kyiv, Ukraine \\ Received 1 August, 2019, accepted 10 December, 2019 \\ Abstract This study presents the results of our comparative evaluation of diagnostic morphological characteristics of raw material from 11 \\ species of genus Thymus L. of medicinal and raw material importance occurring in Ukraine. The following taxa were evaluated: \\ T. serpyllum L., T. odoratissimus Mill. (T. glabrescens Willd.), T. borysthenicus Klokov \& Des.-Shost., T. pallasianus Heinr. Braun, T. \\ moldavicus Klokov \& Des.-Shost., T. calcareus Klokov \& Des.-Shost., T. alpestris Tausch ex A. Kern., T. x dimorphus Klokov \& Des.- \\ Shost., T. pannonicus All. s.l. (including T. marschallianus Willd.), T. pulegioides L. and T. roegneri K. Koch (T. alternans Klokov). \\ Among wild species of thyme, only raw material of Thymus serpyllum is officially allowed for use with the purpose for production \\ of pharmaceuticals and medicines. A comparison of the main characteristics is particularly important in view of the fact that \\ raw material is represented by parts of plants (stems, leaves and flowers), which makes any whole comparison of species hardly \\ possible. This study has revealed that stem pubescence, calyx structure, configuration/arrangement and type of leaf venation can \\ provide valuable information for diagnostics of raw material of Thymus species. The results exhibited that according to characters \\ of stem pubescence, calyx structure, shape and size of leaves the most similar are raw material samples of $T$. serpyllum and \\ T. moldavicus. However, these species are rather well separated geographically, so the possibility of mixing of their raw material \\ is negligible. Other species have significant morphological differences in certain characteristics by which they can be diagnosed \\ in the raw material.
}

Keywords Thymus-morphology-characters-raw material-medicinal plants-Ukraine

\section{INTRODUCTION}

Species of the genus Thymus are valuable natural sources of pharmaceutical raw materials for the pharmaceutical industry and medicine. The raw materials of wild and cultivated species of thyme have been used for a long time to treat and prevent respiratory and other diseases and malfunctions. Representatives of the genus Thymus are included in many pharmacopoeias of Europe, which recommend their use in medicines, balms and biologically active food supplements. Raw materials of wild Thymus serpyllum L. and cultivated Thymus vulgaris L., which are included in the State Pharmacopoeia of Ukraine, are mainly used for the production of medicines in Ukraine (SPhU, 2001, 2004, 2008, 2009, 2011). According to various data, there are from 15 to 40 species of the genus Thymus occurring in Ukraine, depending on different taxonomic treatments and wide versus narrow species concepts applied by various taxonomists (see the list of accepted species and synonyms in Mosyakin and Fedoronchuk, 1999, with updates by Nachychko, 2015). In assessing the current taxonomic status of selected critical taxa, we also consulted the reliable online resources, such as POWO (Plants of the World Online - http://www. plantsoftheworldonline.org). These species differ by their morphological characteristics and territorial distribution. Still at this moment there are questions regarding the taxonomy of species, which belong to this genus due to high population variability and occasional hybridisation, despite the fact that there is abundant data on morphology and micromorphology (Bartolucci et al., 2013, Ložiene, 2006, Morales, 2002, Zeljković

*E-mail:pidchenkovitalii@gmail.com

(c) European Pharmaceutical Journal 
\& Maksimović, 2015, etc.). Species of this genus have a comparatively small number of morphological features that can be used as diagnostic, so the question of interrelations species of thyme, and even the infraspecific versus specific status of some taxa, remains controversial at present.

Among the wide diversity of species and infraspecific entities of thyme in Ukraine, 11 species have the greatest distribution and native resources suitable for harvesting in natural habitats. Most of them are geographically restricted, although sometimes their geographic ranges overlap, and there are known cases of collecting of neighbouring or co-occurring species (Minarchenko, 2011). Such mixed or confused raw material may mistakenly get into production of medicines at pharmaceutical companies. Therefore, the identification of species-specific morphological features of these taxa is important for the diagnostics of raw material.

The main morphological characteristics of species of Thymus for the purposes of taxonomy are quite fully described by many scientists (Gogina, 1975, Ložiene, 2006, and references therein). But many systematically relevant and even reliable characteristics are not applicable to the purpose of identification of raw material, since the raw of thyme is a mixture of fragments of generative and vegetative shoots (stems with leaves), leaves, parts of inflorescences and flowers (or flower parts, such as the calyx and corolla). The aim of this comparative study was to determine morphological features required for the differentiation and identification in raw material of the most commonly occurring species of Thymus in Ukraine.

\section{MATHERIAL AND METHOD}

Taxa of research were above-ground (often termed aerial) parts of T. serpyllum L., T. glabrescens Willd., T. borysthenicus Klokov \& Des.-Shost., T. pallasianus Heinr. Braun, T. moldavicus Klokov \& Des.-Shost., T. calcareus Klokov \& Des.-Shost., T. alpestris Tausch ex A. Kern., T. $\times$ dimorphus Klokov \& Des.-Shost., T. pannonicus All. (T. marschallianus Willd.), T. pulegioides L. and T. roegneri K. Koch (T. alternans Klokov). Considering the fact reported in literature (see above) that the main diagnostic morphological characteristics of the raw materials of thyme species are the pubescence of different organs of plants, the shape and size of leaves, calyx and tooth of upper lip, the main attention was paid to analysing these characteristics.

The research is based on the materials and results of authors' long-term field research at different localities, as well as desktop studies, critical processing of literary sources, and herbarium specimens deposited at the National Herbarium of Ukraine (international acronym KW: http://sweetgum. nybg.org/science/ih/herbarium-details/?irn=125430). KW is the largest herbarium in Ukraine and the second largest in Eastern Europe; it contains trusted scientific collections of Thymus that were critically revised and identified by several distinguished experts in the taxonomy of the genus. For the morphological studies, at least ten specimens of each species were investigated. All measurements were made ten times for each organ from different parts of a specimen. The photographs were taken using the Philip Harris Stereo Microscope and Levenhuk M1000 PLUS Microscope Camera.

\section{RESULTS AND DISCUSSION}

This study is prepared for the purposes of diagnostic of raw material (so-called 'herb') of Thymus species under laboratory conditions using a simple microscope.

\section{Stem (Fig. 1, 2)}

The main diagnostic feature for the stem of Thymus species is its pubescence and its peculiarities (pubescence on ribs, opposite margins or all faces, size and density of trichomes and so on), as well as the degree of the ribs manifestation, the presence of glandular trichomes and branching of generative shoots.

The character of stem pubescence is a rather stable morphological characteristic of Thymus species, although some species may vary by that character in their upper and lower parts of stems (Nachychko, 2015) or on generative and vegetative stems (Kamašina, Loțienë, 2009). While the raw material of thyme is the upper frondose (leaf-bearing, usually with inflorescences) part of the shoot, these differences are insignificant.

Comparative morphological analysis showed that the pubescence all around the stem is present in $T$. serpyllum, T. borysthenicus, T. calcareus, T. dimorphus, T. glabrescens, T. moldavicus, T. pallasianus and T.pannonicus (Fig. 1). Their stems are hairy all over with non-glandular, mostly multicellular, more or less curved hairs. The stems of vegetative shoots are pubescent with shorter trichomes than the stems of generative ones in all species. However, the stems of the analysed species have a number of distinctive features. Short and sparse stem trichomes are present in T. borysthenicus and T. pallasianus, while the stems of $T$.calcareus and $T$. moldavicus have short thick tectorial trichomes. Stems of $T$. serpyllum, T. dimorphus, T. glabrescens and T. pannonicus are thickly covered by the protruded long trichomes. Secretory (glandular) trichomes are rarely distinctly shown on the stems of T. serpyllum, T. dimorphus, T. moldavicus and T. pannonicus (Fig. 1a, d, f, h). The secretory trichomes on the stem are mostly represented by multicellular glands that are prominent above the verge of stem, and their density increases from the base to the apex of the stem. This is typical for many species of the genus, as well as the stem pubescence (Boz et al., 2009, Nachychko, 2015).

At the stems of generative shoots of $T$. alpestris and $T$. pulegioides the multicellular trichomes are present only along the ribs (Fig. 2a, b); the glandular trichomes are scarce. Stems of $T$. roegneri are pubescent with long multicellular hairs on 

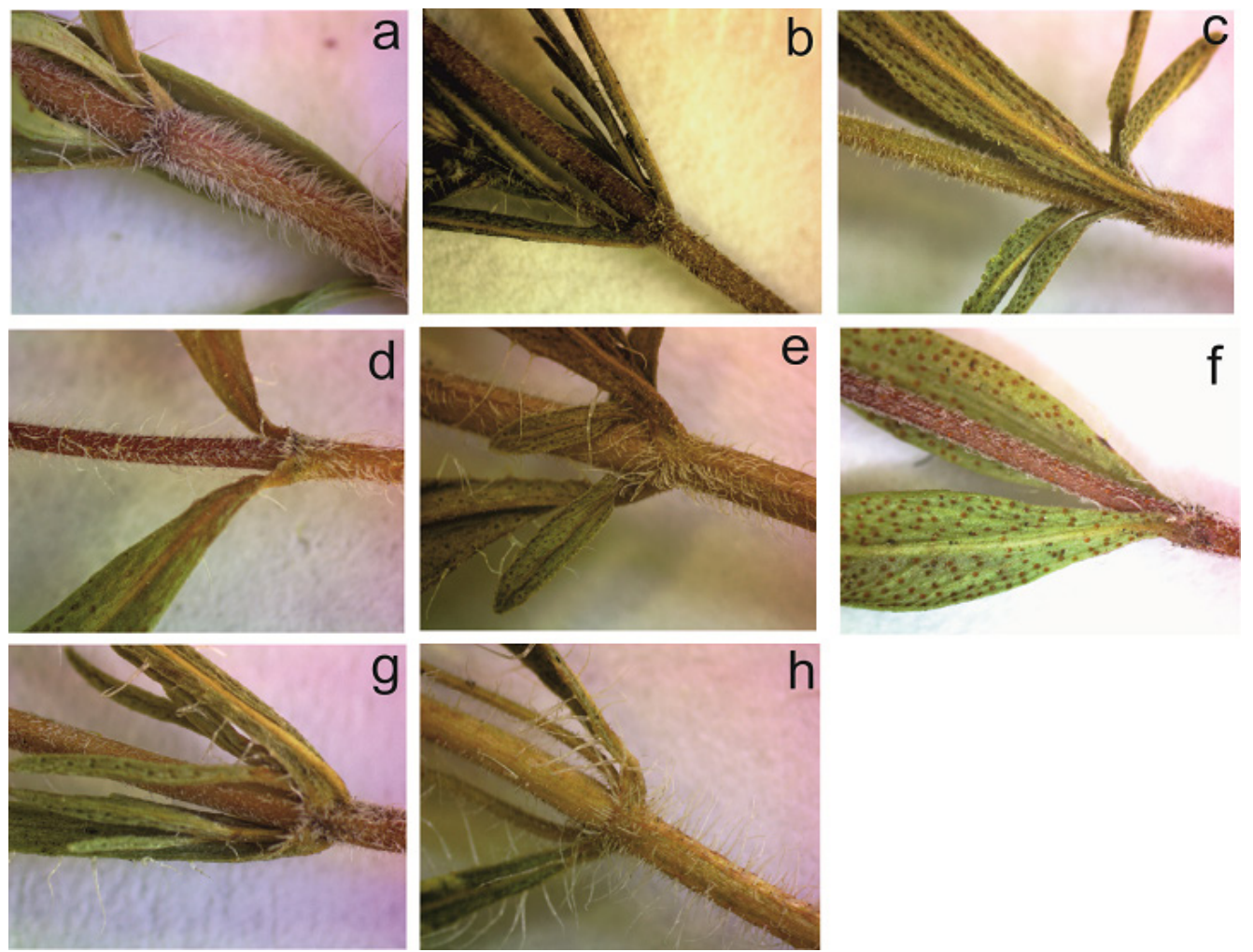

Figure 1: All-around stem pubescence of selected Thymus species, $\times 20: a-T$. serpyllum, $b-T$. borysthenicus, $c-T$. calcareus, $d-T$. dimorphus, $e-T$. glabrescens, $f-T$. moldavicus, $g-T$. pallasianus, $h-T$. pannonicus.
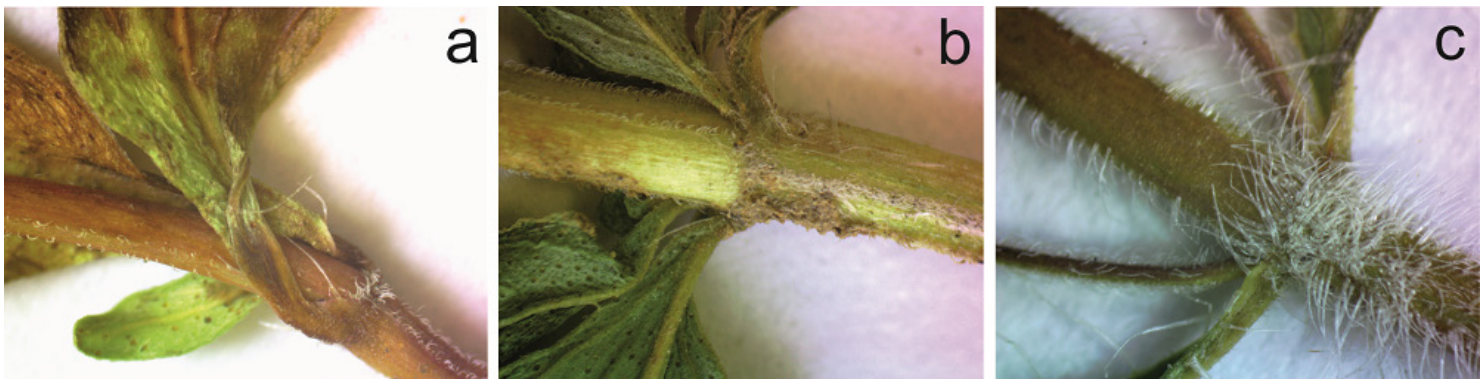

Figure 2: Stem pubescence along the ribs ( $a-$ T. alpestris, $b-$ T. pulegioides, $c-$. roegneri) and on opposite faces, $\times 20$.

two opposite faces (Fig. 2c), alternately from verge to verge; the glandular trichomes are less distinguished.

\section{Leaf blade (Fig. 3-5)}

In raw materials of thyme the leaves are more distinguished. They differ in size, shape, pubescence of the leaf blade and edge of the blade, type of venation and frequency of occurrence of glandules. It has been established that the size of leaves in all species of thyme varies markedly depending on the stage of development and location on the stem. In addition, it is believed that the size of the leaves and the ratio of their length and width are significantly influenced by environmental conditions (Ložiene, 2006). However, the shape of the leaf blade is a more stable feature.

The brevipetiolate (short-petioled) linearly elongated or elongated-elliptical leaf shape is present in T. serpyllum, $T$. moldavicus and T. calcareus, broadly-elliptical in T. roegneri and T. glabrescens. The manifestation of leaves polymorphism of different formations is customary for T. glabrescens (Nachychko, 2015). Though, within the limits of one generative shoot the leaves differ both in form and in degree of development of petioles on upside and basal part. The needle-shaped or narrow-linear leaves with involute edge of leaf blade are present in T. borysthenicus and T. pallasianus (Fig. 3). Thymus dimorphus and T. pannonicus have sessile 

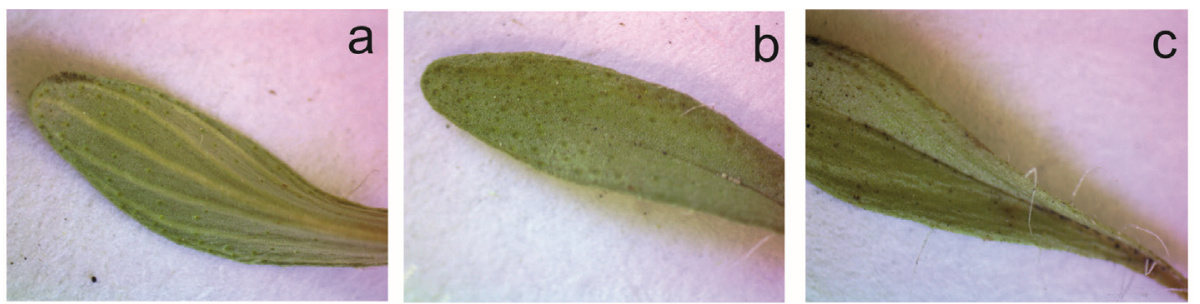

T. serpyllum
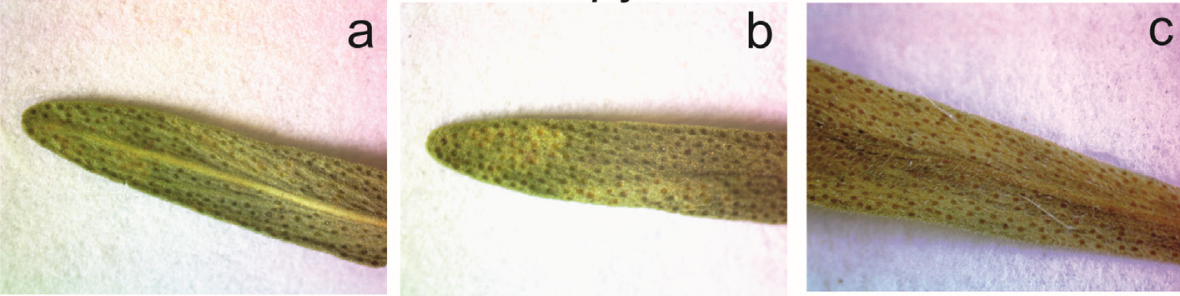

T. calcareus

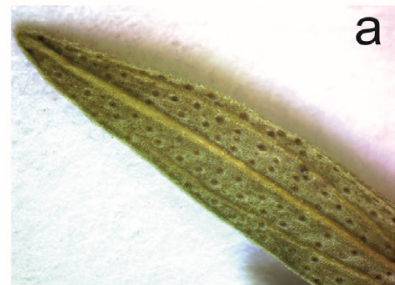

a

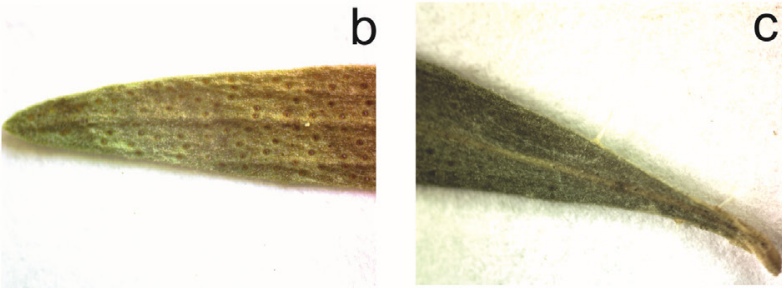

T. dimorphus
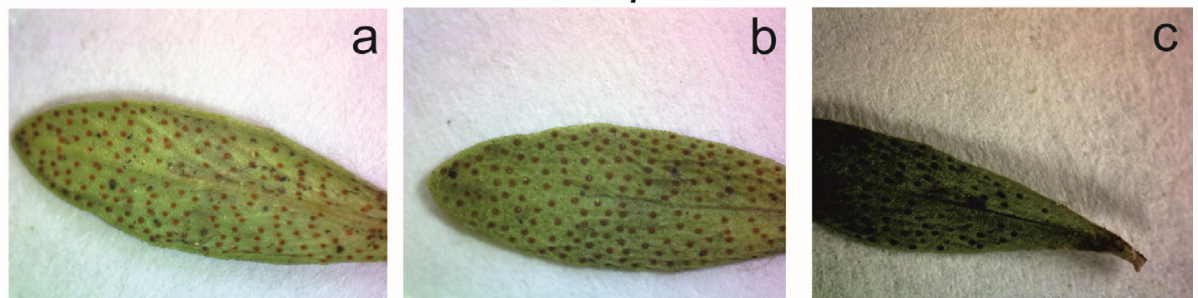

T. moldavicus
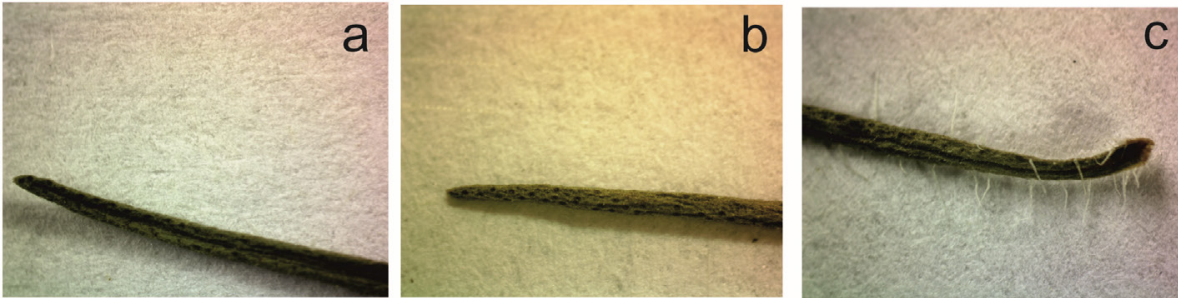

T. borysthenicus
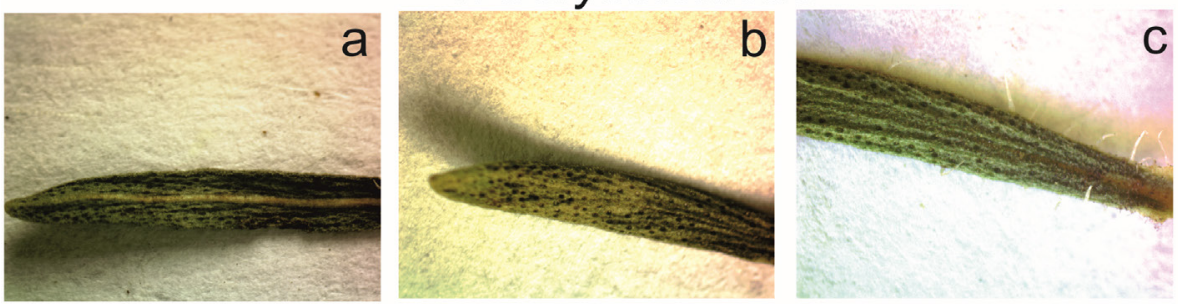

T. pallasianus

Figure 3: An important diagnostic characteristic of leaf blade of selected Thymus species, $\times 20: a-a b a x i a l ~ l e a f ~ s u r f a c e s, ~ b-a d a x i a l$ leaf surfaces, $c$ - leaf base. 

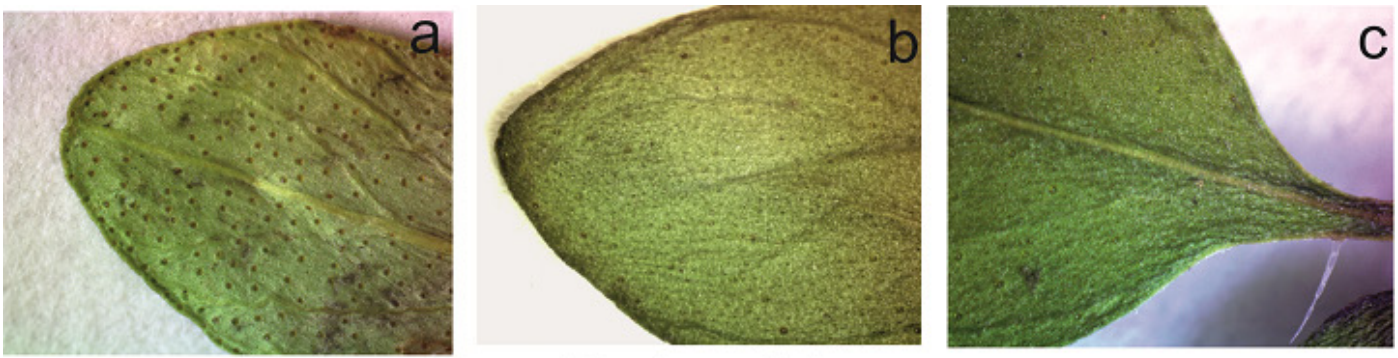

T. alpestris
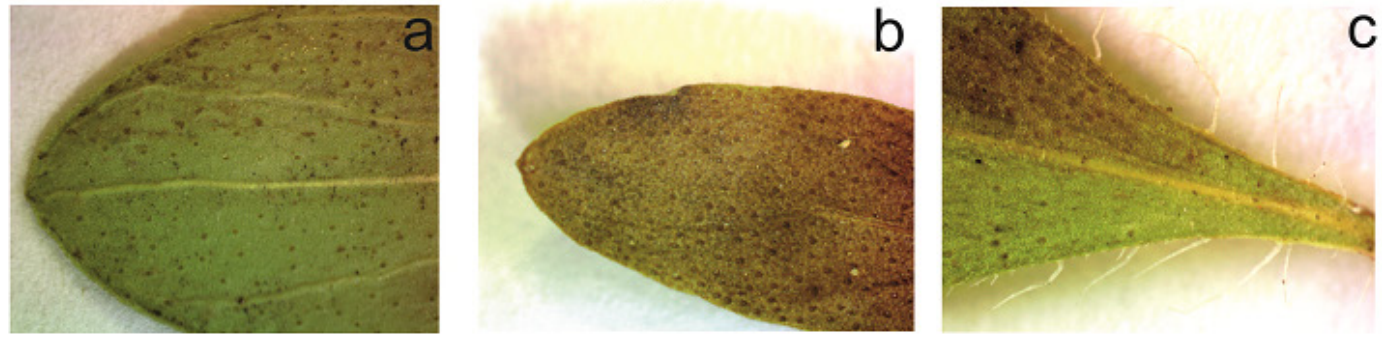

T. glabrescens
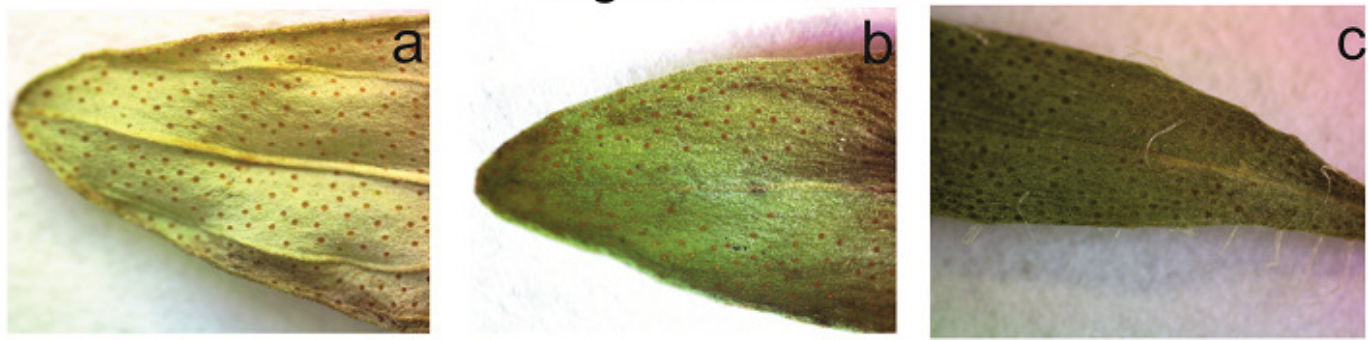

\section{T. pannonicus}

a
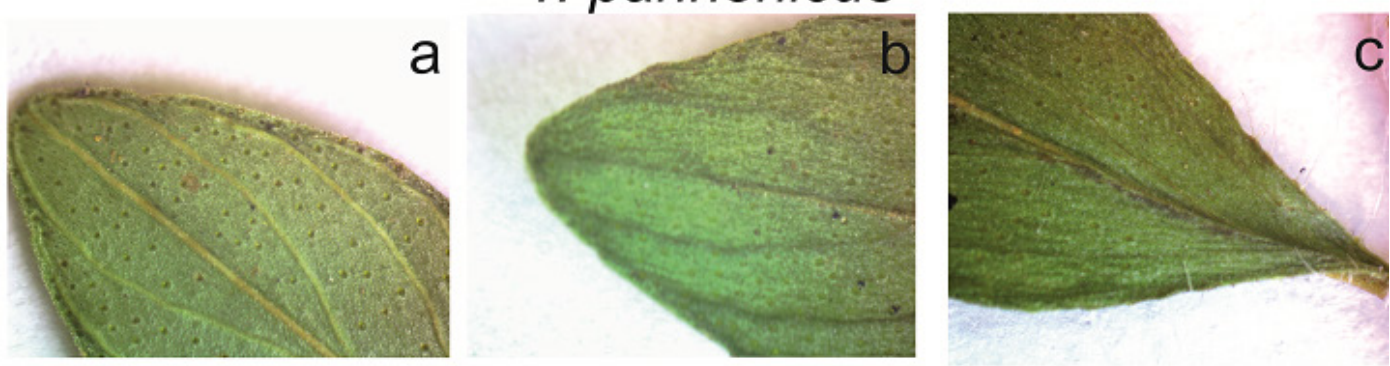

\section{T. roegneri}
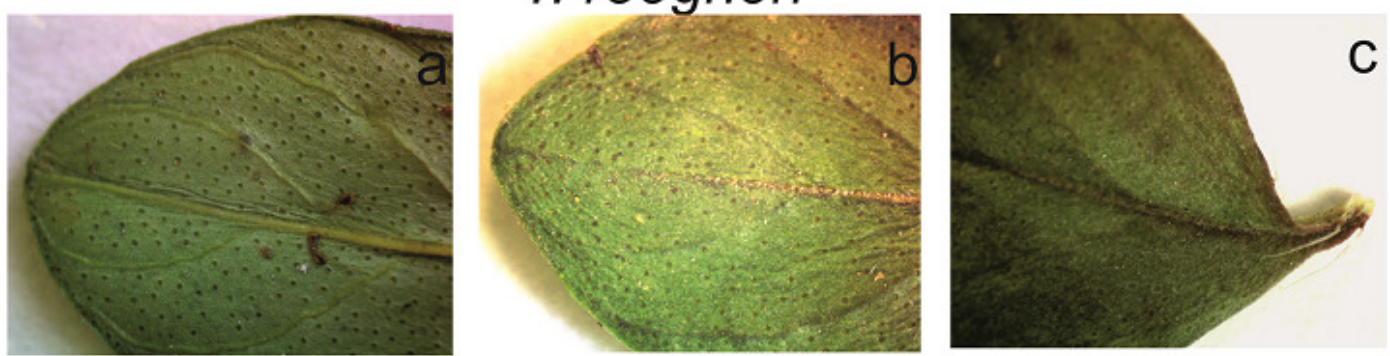

\section{T. pulegioides}

Figure 4: An important diagnostic characteristic of leaf blade of selected Thymus species, $\times 20: a$ - abaxial leaf surfaces, $b$ - adaxial leaf surfaces, $c$ - leaf base. 


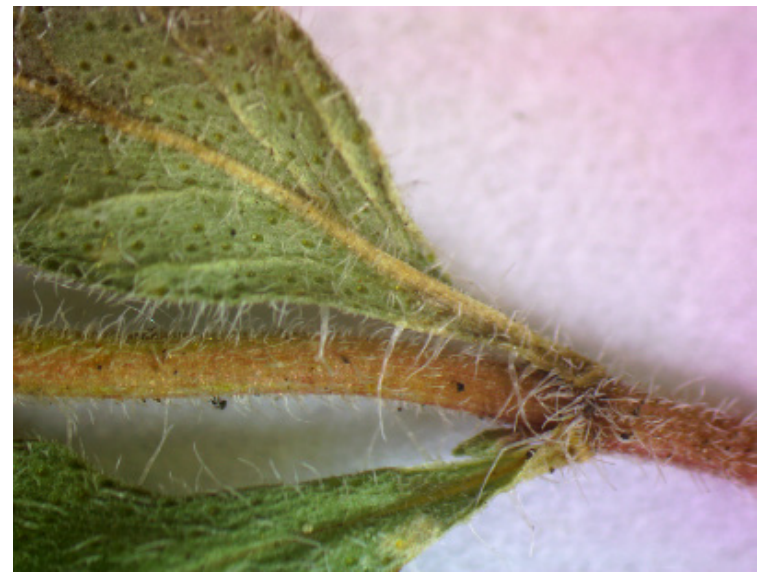

Figure 5: Multicellular trichomes on both sides of the T. pannonicus leaf blade, $\times 20$.

(narrowed at the top, tapered at the base) or brevipetiolate elongated-elliptical leaves (Fig. 3, 4). The considerable variability of leaf blade pubescence of $T$. pannonicus was found in some populations. The leaves of some species are pubescent with multicellular trichomes on both sides of the leaf blade (Fig. 5), although in the most of analysed specimens these trichomes are present only on the edge of the leaf blade at the base. Leaves of T. alpestris and T. pulegioides are wide, egg-shaped with the largest width in the middle of the leaf blade and well-defined petiole.

The leaves of Thymus species are thickly covered by tectorial short non-glandular trichomes on both sides of the lamina (Fig. 3, 4) and, therefore, the leaves appear greyish. This is especially peculiar to leaves of $T$. serpyllum, $T$. calcareus, $T$. dimorphus, T. moldavicus, T. borysthenicus and T. pallasianus (Fig. 4). In other species it is less pronounced.

Multicellular unbranched trichomes along the edge of the leaf blade are present in all species. They usually occur in the lower third of the leaf, although sometimes they rise higher. Size, shape and colour of the glandular trichomes on the stems, adaxial and abaxial leaf surfaces and calyx differ in the studied species less.

The number and density of glands (capitate and peltate glandular trichomes) on both surfaces of the leaves vary considerably even in populations of one species (Arsenijević et al., 2019, Dajić-Stevanović et al., 2008), therefore these criteria have no significant diagnostic value for raw material of thyme. At both dorsal and ventral sides of leaves of most species, the glands are rather evenly distributed (Fig. 3, 4). It has been affirmed that two surfaces of leaves of $T$. serpyllum contain approximately the same quantity of these glandular trichomes, though the adaxial surface of $T$. vulgaris leaves has more glandular trichomes compared to the abaxial surface of ones (Svidenko et al., 2018). The density of glandular trichomes is distinguished for considerable diversity and variability; particularly it can depend on both ecological and genetic factors. In general, their density is higher in species with small leaves except T. serpyllum (Fig. 1a, b).

The type of leaf venation is an important systematic characteristic of thyme leaves, but diagnosing of thyme raw materials only by this characteristic is complicated by blurriness or the weak expression of this trait and the lack of clear differences in the venation. For example, we can see that the central and lateral veins of leaf protrude above the abaxial surface of the leaf blade in T. alpestris, T. glabrescens, $T$. pannonicus and $T$. roegneri, and the lateral veins are arcuately curved, gradually thin out as they approach the edge of the leaf blade and do not merge together at the edge (eucamptodromous venation) (Fig. 4a). In T. pulegioides and $T$. serpyllum the upper lateral veins merge together at the edge of the leaf blade. However, the lateral veins of $T$. pulegioides are arcuately bent, and acute angles to the central vein are present in T. serpyllum. The central and lateral veins are more or less distinguishable in T. dimorphus, and the lateral veins are scarce and elongated upwards at a slight angle to the central vein, but they do not merge at the apex, as in T. serpyllum.

The leaves of $T$. borysthenicus, $T$. calcareus, T. moldavicus and $T$. pallasianus are similar in venation, but even here some differences are present (Fig. 3). The lateral veins on the abaxial surface of $T$. calcareus and $T$. pallasianus leaves are better pronounced than in T. moldavicus. The distinguishing of the central and lateral veins in the leaves of $T$. borysthenicus is difficult. The results of our observations demonstrated that in some cases it is difficult to determine the distinctions in venation of leaves in different species. Therefore, this character (or, rather, set of characters) can only be used in combination with other diagnostic speciesspecific features.

\section{Calyx (Fig. 6, 7).}

Calyx structure is a species-specific feature in thyme, particularly length and shape of calyx, the shape of the teeth of upper lip of calyx and the pubescence of the teeth of lower lip of calyx. The trumpet elongated-campanulated calyx with numerous (more than 12 pairs) long trichomes on the teeth of the lower lip is present in T. borysthenicus, $T$. calcareus, T. moldavicus, T. pallasianus and T. serpyllum (Fig. 6). The glandular trichomes are present across all surfaces of the calyx of all analysed species.

The calyx of T. alpestris, T.dimorphus, T. glabrescens, $T$. pannonicus, T. pulegioides and T. roegneri has a predominantly widened extended-campanulate shape with a few (up to 12 pairs) scattered long trichomes on the teeth of the lower lip (Fig. 7).

It is believed that these structural features of the calyx within the genus of Thymus are quite conservative and rather constant at the section level, so they are often used for taxonomy purposes (Gogina, 1975, Nachychko, 2015). According to the results of our analysis, the characteristics of the calyx structure, especially its length and shape, have 

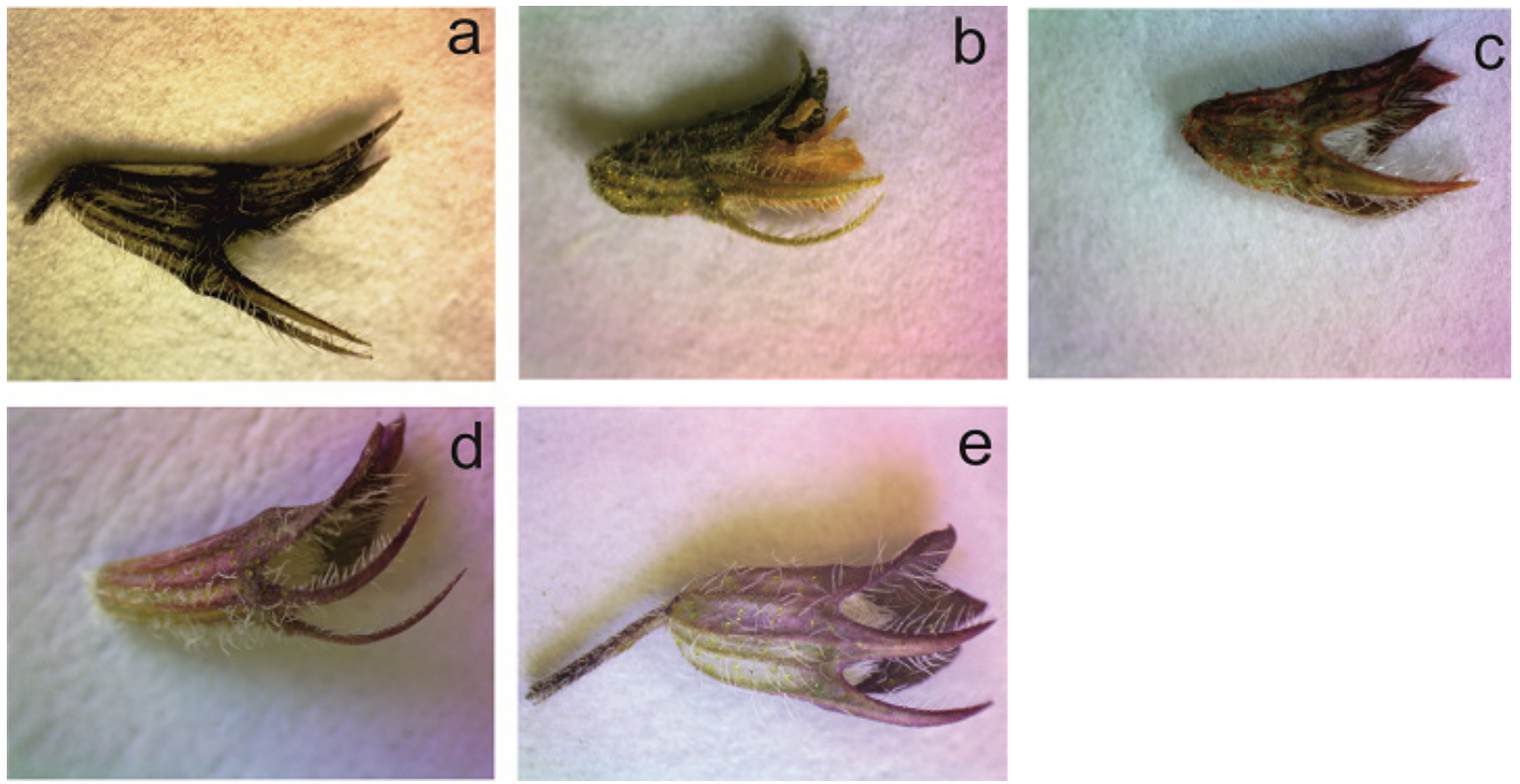

Figure 6: Calyx with numerous (more than 12 pairs) long trichomes on the teeth of the lower lip of selected Thymus species, $\times 20: a-$ T. borysthenicus, $b-T$. calcareus, $c-T$. moldavicus, $d-T$. pallasianus, $e-T$. serpyllum.
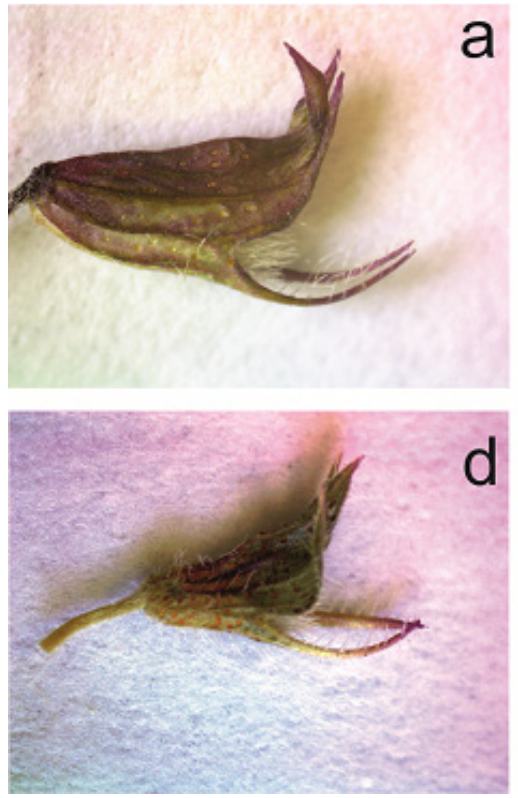
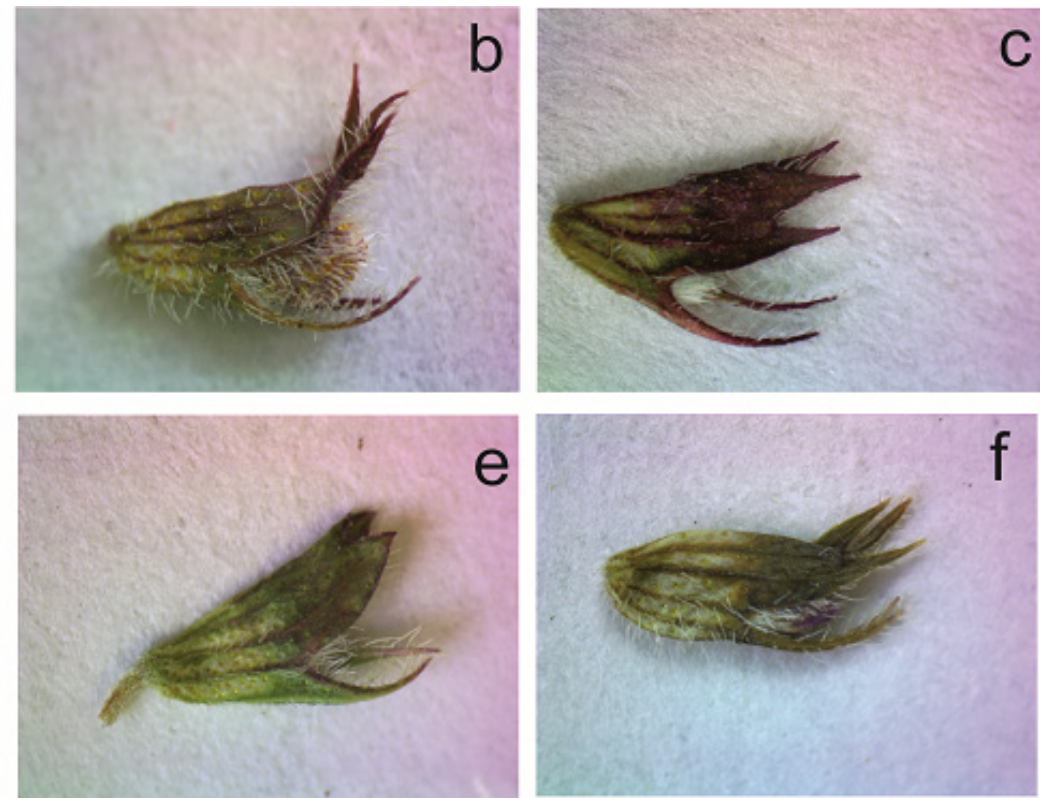

Figure 7: Calyx with few (up to 12 pairs) scattered long trichomes on the teeth of the lower lip of selected Thymus species, $\times 20: a-T$. alpestris, $b-T$. dimorphus, $c-T$. glabrescens, $d-T$. pannonicus, $e-T$. pulegioides, $f-T$. roegneri.

a significant range of variability and in species with multiflowered inflorescences can vary greatly, depending on their position in the inflorescence, which complicates their comparison in raw material. Therefore, it has been found that structure of the thyme calyx could be useful for distinguishing the raw materials of Thymus species in addition to other morphological characteristics mentioned above.

\section{CONCLUSIONS}

The investigation of the morphology of raw parts of 11 species of Thymus most commonly occurring in Ukraine was carried out using a light microscope. The diagnostic features of leaves, stem and calyx of these species from different regions were studied and described. The results of analyses demonstrated that raw material of T. serpyllum is similar to 
that of other Ukrainian species of genus; however, it has a number of diagnostic morphological characteristics. The values of the analysed parameters do not have a universal range and are often variable within wide limits, depending on various environmental factors. Raw material of any of the studied species can be clearly distinguished from that of other taxa only through the use of the whole complex of species-specific morphological characteristics. This study is aimed at facilitating the identification of thyme raw material and might be further used for the development of regulatory documents on this herbal medicinal material, at least within the study area (Ukraine and adjacent areas).

\section{ACKNOWLEDGEMENTS}

The authors are grateful to Sergei L. Mosyakin, Director of M.G. Kholodny Institute of Botany of National Academy of Sciences of Ukraine, and Natalia M. Shyian, Head Curator of National Herbarium of Ukraine (KW), for providing necessary research facilities. The valuable comments and suggestions of two anonymous reviewers on the earlier version of the manuscript are greatly appreciated, as well as comments of the editorial team, which greatly improved the text.

\section{References}

[1] Arsenijević J, Drobac M, Šoštarić I et al. Comparison of essential oils and hydromethanol extracts of cultivated and wild growing Thymus pannonicus All. Industrial Crops and Products. 2019;130:162-169.

[2] Bartolucci F, Peruzzi L, Passalacqua N. Typification of names and taxonomic notes within the genus Thymus L. (Lamiaceae). Taxon. 2013;62(6):1308-1314.

[3] Boz I, Burzo I, Zamfirache MM, Toma C, Padurariu C. Glandular trichomes and essential oil composition of Thymus pannonicus All. (Lamiaceae). An. Univ. Oradea. Fasc. Biol. 2009;16(2):36-39.

[4] Boz I, Navarro L, Gales R, Padurariu C. Morphology and structure of glandular hairs in development of Thymus vulgaris L. Scientific Annals of Alexandru loan Cuza University of lasi. New Series, Section 2. Vegetal Biology. 2009;55(2):81-86.

[5] Dajić-Stevanović Z, Šoštarić I, Marin PD, Stojanović D, Ristić M. Population variability in Thymus glabrescens Willd. from Serbia: morphology, anatomy and essential oil composition. Arch. Biol. Sci., Belgrade. 2008;60(3):475-483.

[6] Gogina EE. Genus thyme (thyme) Thymus L. Biological flora of the Moscow region. 1975;2:137-168. (in russian)

[7] Kamašina V, Loțienë K. The evaluation of phenotypic diversity of Thymus $\times$ Oblongifolius according to some anatomical characters and comparison with parent species. Acta Botanica Hungarica. 2009;51(1-2):105-117.

[8] Loțienë K. Instability of morphological features used for classification of Thymus pulegioides infraspecific taxa. Acta Botanica Hungarica. 2006:48(3-4):345-360.

[9] MinarchenkoV. Medicinal plants of Ukraine: diversity, resources, legislation. Medicinal plant conservation. 2011;14:7-13.

[10] Morales R. The history, botany and taxonomy of the genus Thymus. In: Stahl-Biskup E, Sáez F, eds. Thyme: the Genus Thymus. London: Taylor and Francis; 2002:1-43.

[11] Mosyakin SL, Fedoronchuk MM. Vascular plants of Ukraine. A nomenclatural checklist. Kiev; 1999. xxiii+345p.

[12] Nachychko VO. Diagnostic features of representatives of Thymus sect. Serpyllum and T. sect. Marginati (Lamiaceae). The Journal of V.N. Karazin Kharkiv National University. Series: biology. 2015;25:77-89. (in ukrainian)
[13] Svidenko L, Grygorieva O, Vergun O et al. Characteristic of leaf peltate glandular trichomes and their variability of some lamiaceae martinov family species. Agrobiodiversity for improving nutrition, health and life quality. 2018;2:124-132.

[14] The State Pharmacopoeia of Ukraine. State Enterprise «Scientific and Expert Pharmacopoeial Centre». 1st ed. Kharkov: RIREH, 2001. Appendix 1. 2004. Appendix 2. Kharkov: State Enterprise «Scientific and Expert PharmacopoeialCenter»; 2008. Appendix 3. 2009. Appendix 4. 2011 (in Ukrainian).

[15] Zeljković SĆ, Maksimović M. Chemical composition and bioactivity of essential oil from Thymus species in Balkan Peninsula. Phytochemistry Reviews. 2015;14(3):335-352. 